\title{
POSSIBILITIES OF TREATMENT OF HIV/AIDS AND OTHER SEXUAL DISEASES USING PHYTOTHERAPY
}

\author{
RAMIZA IDRIZOVIC ${ }^{1}$, BRANKICA DUPANOVIC ${ }^{2}$, MILAN JOVANOVIC ${ }^{3}$, MILENA DJUROVIC ${ }^{4}$ \& \\ BOGDANKA ANDRIC ${ }^{5}$ \\ ${ }^{I}$ Research Scholar, Private Clinic, Zelenkada, Bijelo Polje, Montenegro \\ ${ }^{2,3,5}$ Research Scholar, Clinic of Infectious Diseases, Medical Faculty, University of Montenegro, Podgorica, Montenegro \\ ${ }^{4}$ Research Scholar, Medical Faculty, Department of Dermatovenerology, University of Montenegro, Podgorica, Montenegro
}

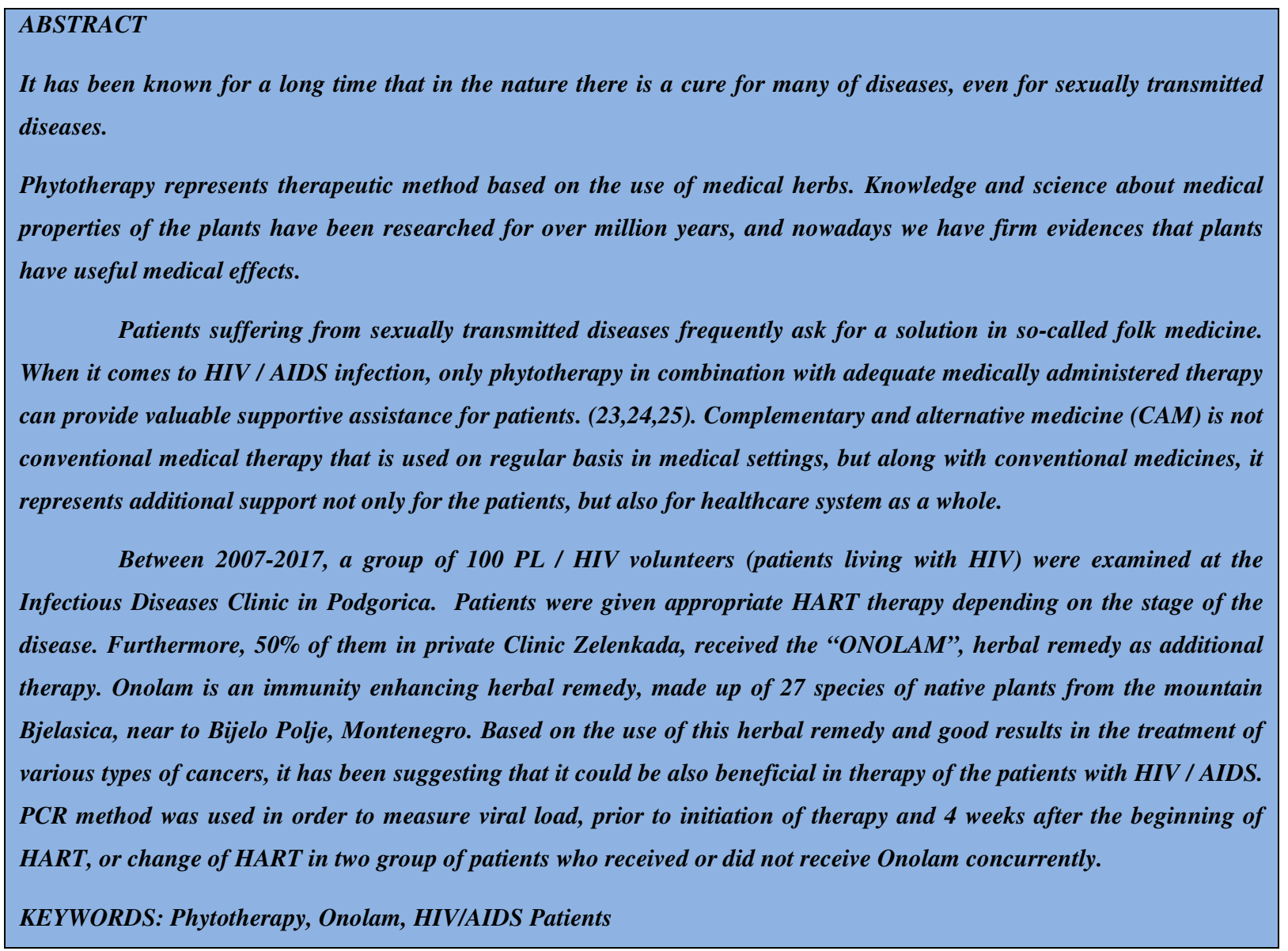

Received: Jun 06, 2020; Accepted: Jun 26, 2020; Published: Jun 30, 2020; Paper Id.: IJMPERDJUN2020148

\section{INTRODUCTION}

Sexually transmitted diseases in modern society represent significant socio-medical problem (1, 2).The most frequent and significant sexually transmitted diseases are: Chlamydia infections, syphilis, gonorrhea, HPV infections, HIV, Herpes infections, Hepatitis B and Hepatitis C, candidiasis, trichomoniasis, veneral lymphogranuloma and others. $(3,4,5)$

Symptoms that may be suspect of sexually transmitted diseases are primarily local (itching and pain in the genital region), dysuria, and increased vaginal secretion, bleeding during or after intercourse, genital warts, 
enlargement of regional lymph glands (4). General symptoms usually emerge later. However, in some sexually transmitted diseases, the symptoms are absent or very discreet and they can be easily overlooked. Modern medicine has successfully prevented and treated many sexually transmitted diseases, but there are also numerous problems associated with the successful treatment, cure and occurrence of complications. $(2,4)$

HIV/AIDS are two stages of infection caused by the Human Immunodeficiency Virus (HIV). The infection progressively destroys the immune system, moving up to the terminal phase- AIDS $(5,6)$. It is cause by a non-oncogenic retrovirus, a subfamily of lent viruses. It is characterized by remarkable abilities of mutations, genetic variations, significant for the time evolution of HIV infection. (7). Development of immunodeficiency is a consequence of affected CD4+T lymphocytes and cells of the monocyte - macrophage line. Gradual elimination of entire clones of CD4+T lymphocytes, primarily memory phenotype (CD45RO), lead to the formation of holes in the immune memory and a decrease in the immune response to HIV, and later to other endogenous and exogenous infections, whose control requires a proper function of cellular (CIO) and humoral (HIO) immunity (8,9,10). The consequences are increased sensitivity of the patient to a series of opportunistic infections, co-infections, tumors with significantly more severe clinical forms of the disease. The acute phase is in most cases asymptomatic. Chronic infection is lifer long and requires lifetime treatment (11, $12,13)$.

Thirty years after the discovery of the causative agent, the global HIV/AIDS pandemy continues to persist, with 78 million people reported worldwide and a trend of further growth. Furthermore, there are around 36 milion currently living with HIV/AIDS (UNAIDS 2016). (13, 14)

The aim of antiretroviral therapy is to achieve the strong suppression of viral replication and undetectable viremia (viral load <50). HART, used in treatment of HIV positive patients represents the simultaneous administration of multiple drugs. The efficacy of therapy is evaluated based on the following: attainment of undetectable viremia 6-8 weeks after the initiation of therapy, limited generation of new HIV variants (quasi-species), reconstruction of CD4 + T lymphocytes, delay of predominance of therapy-resistant genotypes, and clinical signs of recovery (regression of opportunistic infections). $(15,16,17)$

The introduction of the powerful concept of HART in 1996 dramatically altered the future of HIV infection, turning it into a chronic and not necessarily a deadly disease (16). Therapeutic compliance and monitoring the infection are essential for the success of therapy.(18) In late presenters of deep immunodeficiency, HART triggers the recovery of the immune system, which may be accompanied by the occurrence of complications called immune reconstruction inflammatory syndrome (IRIS). This syndrome is a consequence of a renewed immune response to specific infectious and non-infectious factors. $(19,20,21,22)$.

Patients, suffering from sexually transmitted diseases, infrequently seek for a solution in so called "folc" medicine. When it comes to HIV / AIDS infection, only phytotherapy in combination with adequate medically administered therapy can provide valuable supportive assistance. $(23,24,25)$

It has beenknowledge for a long time that in nature there is a cure for everything, as well as for sexually transmitted diseases. $(26,27,28)$. In addition to the medical treatment of syphilis, the use of the plants, such as sassafras (grows in America and Asia), lemons, boxwood, thistles, common soapwort, herb day and night, give a significant contribution to antibiotic therapy which is particularly important for the patients resistant to the standardized antibiotic 
therapy. Danderlion of milk of thistle and licorice can be used as an adjuctive therapy for hepatitis B while in hepatitis C willow, ruse and thistle tea can be used as a supportive therapy (29). Also wormwood, cat's claw, Echinacea, are some of the plants that besides enhancing the immune system have strong antibacterial properties, which makes them suitable for the treatment of inflammatory processes, for example Chlamydia infections. The herbal medicine for genital warts is tincture thuja (treatment is carried out by tropical coating of genital warts 2 times a day). Dandelion or milk of thistle and licorice it has been known for a long time that in nature there is a cure for everything, as well as for sexually transmitted diseases.

\section{METHODOLOGY}

Between 2007-2017, a group of 100 PL / HIV volunteers (patients living with HIV) were examined at the Infectious Diseases Clinic in Podgorica. Patients were given appropriate. HART depending on the stage of the disease.

Furthermore, $50 \%$ of them in private Clinic Zelenkada, received the "ONOLAM", herbal remedy as additional therapy. Onolam is an immunity enhancing herbal remedy, made up of 27 species of native plants from the mountain Bjelasica, near to Bijelo Polje, Montenegro. Based on the use of this herbal remedy and good results in the treatment of various types of cancers, it has been suggested that it could also beneficial for the patients with HIV / AIDS. PCR method was used in order to measure viral load, prior to initiation of therapy and 4 weeks after the beginning of ART or change of ART in patients who received or did not receive Onolam concurrently.

\section{RESULTS}

Montenegro is small country in Balkan /Mediterranean area. The most common way of transmitting HIV / AIDS infection in our patients is through sexual intercourse (heterosexual and homosexual). Figure 1.

Of the 100 PL / HIV patients receiving appropriate ART therapy at the Clinic for Infectious Disease in Podgorica, about $50 \%$ of them volunteered to receive for additional supportive therapy with the herbal remedies Onolam at the Private Clinic "Zelenkada" in Bijelo Polje.

A total of $50 \mathrm{HIV/AIDS}$ volunteers were interviewed and included in the analysis. About 41

$(82 \%)$ of the study participants were males and $9(18 \%)$ females. The ages of patients has range to $18-47$ years. Majority of responders $(76 \%)$ were from urban areas. 


\section{EPIDEMIOLOGIC IMAGE - MONTENEGRO}

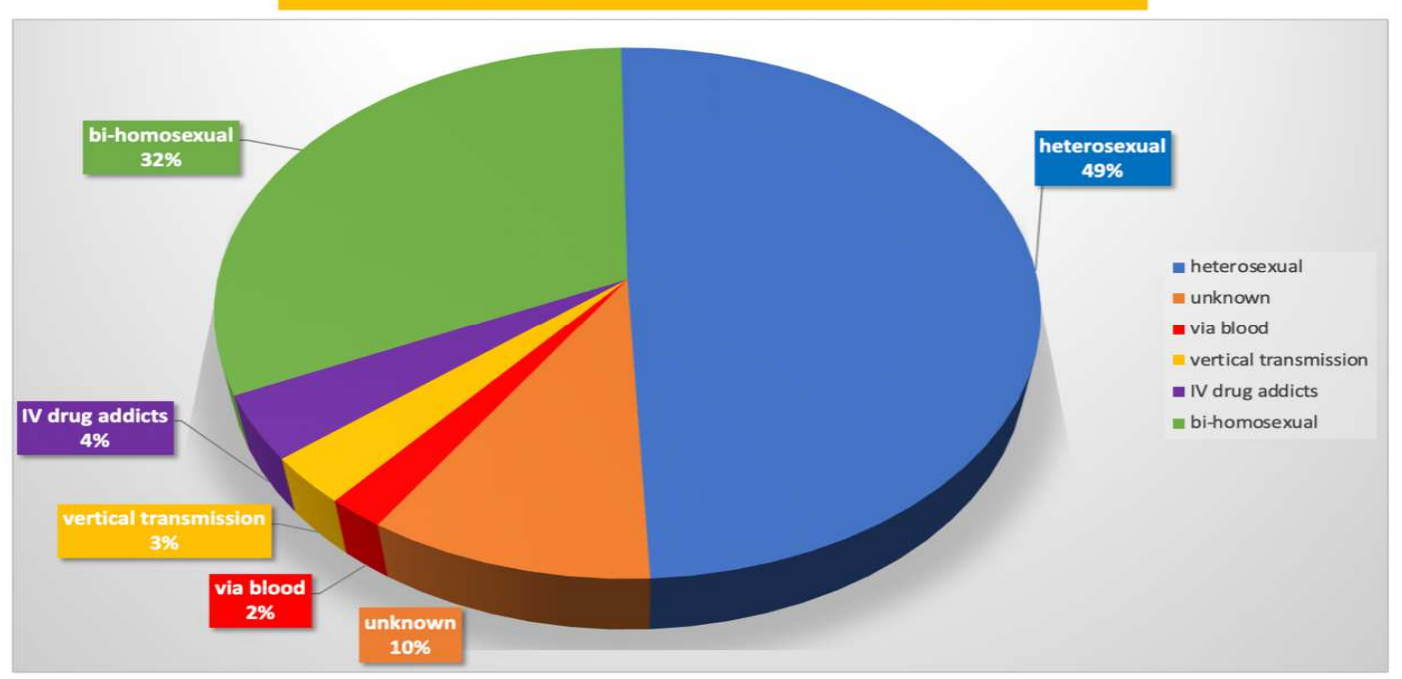

Figure 1: In Montenegro the Most Common Vay of HIV Transmission is trough Intercourse.

HIV multiplies in CD4 cells. This process goes through several stages. CD4 Correlated with basic complication during HIV infection. (Figure 2)

\section{CLINICAL PROGRESSION OF HIV INFECTION}

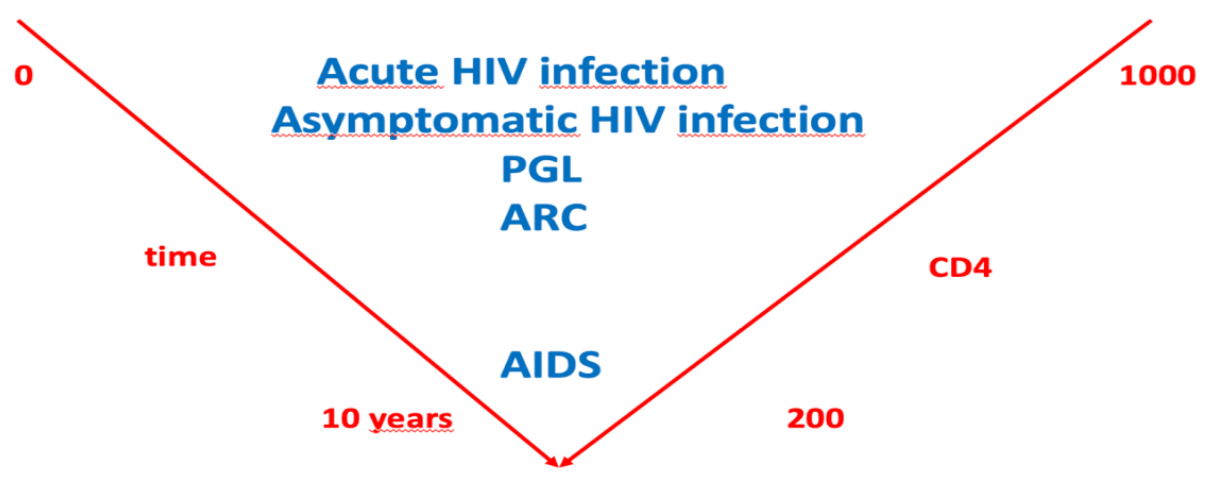

Figure 2: Clinical Progression of HIV Infection.

Different types of anti HIV drugs act at different stages of the viral life cycle. There are 4 major stages in this cycle in which there are 4 classes of anti-HIV drugs: Nucleoside reverse transcriptase inhibitors (NRTIs), non-nucleoside reverse transcriptase inhibitors (NNRTIs), Protease inhibitors (PIs), Fusion inhibitors (FIs) (Figure 3). 


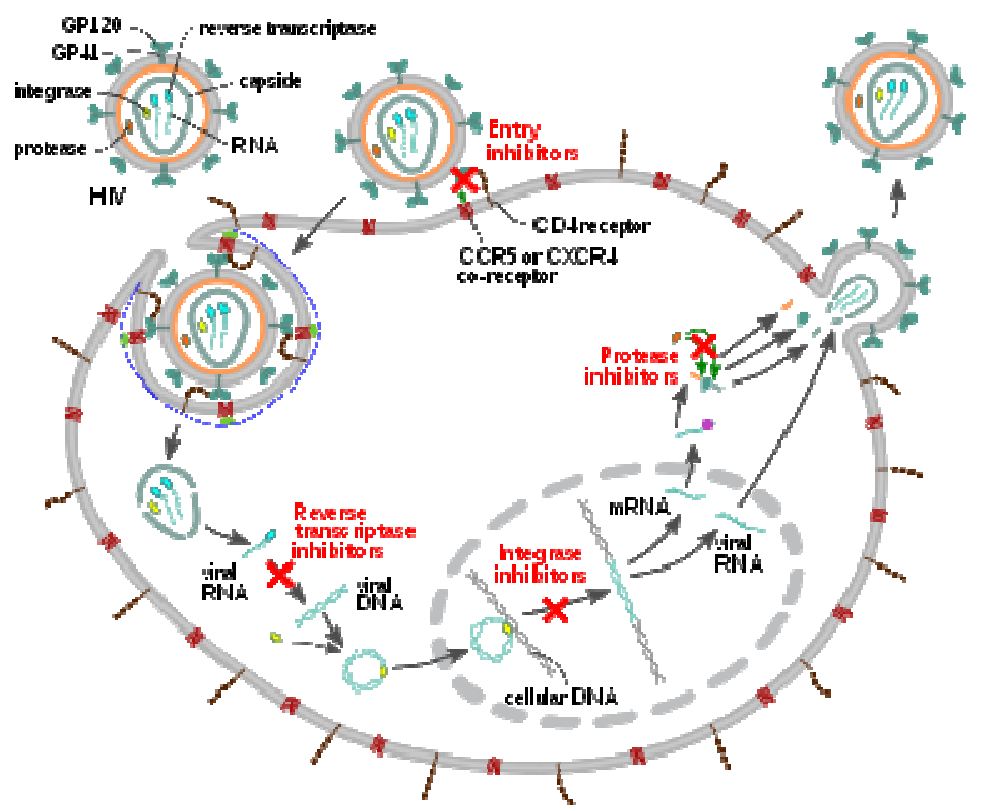

Figure 3: Schematic Description of the Mechanism of the Four Classes of Currently Available Antiretroviral Drugs Against HIV.

In the group of 50 patients with PL/HIV who did not receive Onolam, in $30 \%$ of patients the viral load was still above 400 copies / $\mathrm{ml}$ after $3-4$ months or above 50 copies / $\mathrm{ml}$. after 6 months. That was an indication to change the therapy, based on the results of resistance tests and the amount of medications in blood. Resistance can develop even when the viral load is between 50 and 500 copies $/ \mathrm{ml}$.

In 50 patients with PL/HIV who received Onolam along with specific therapy, no complications or development of resistance to specific therapy for HIV infection occurred in either case.

Combined treatment of Onalam and antiretroviral agents showed increased antiviral benefit compared with antiretroviral alone in these patients.

Almost all sexually transmitted diseases can be treated with supportive phytotherapy, besides the primary therapy. In the present era of resistance towards many medications, phytotherapy contributes to the successful management of these infections.

\section{DISCUSSION}

Patients living with HIV / AIDS often seek alternative or "complementary" therapies for their illness. Among the numerous studies of therapeutic options, few have met the scientific standards to support claims about the beneficial effects of the therapies studied. $(24,25,26,27)$.

Phytotherapy presents a therapeutic method based on the use of medicinal herbs. Traditional, or folk medicine is based on the use of plants and herbal derivates for healing, and it represents one of the oldest ways for treating STDs, which is as old as humanity. Herbal treatments developed and practiced worldwide in accordance with the climate in which herbalists or scientists live in; they have learned to use the plants that are available in area they live and work in (30,31). Knowledge about the medicinal properties of the plants has been accumulated over the million years. Herbalism is based 
on the traditional use of plants, regardless of the scientific confirmation or confirmation of the medicinal properties of a particular plant. (32)

Our investigations are based on years of practical experience with Onalam and its beneficial effects in treating certain malignancies. The basic effect of this herbal therapy, as the supportive therapy of a specific combination of antiHIV / AIDS drugs, has been proved as effective. In 50 patients with PL / HIV who received "Onolam" along with specific therapy, no complications or development of resistance to specific therapy for HIV infection occurred in either case.

Intensive high-active antiretroviral therapy (HAART), which generally involves administering at least one protease inhibitor in combination with other antiretroviral drugs, is today a therapeutic standard, mostly because of its increased efficacy over the earlier administration of two drugs or even one drug. However, this therapy also carries the risk of serious side effects such as the multicenter form of special lymphatic hyperplasia. The dilemma of whether this phenomenon is related to HAART itself is not fully defined; therefore, it calls for extreme caution when administering such intensive therapeutic treatments. It has been proven that the presence of other infections can also adversely affect viral load. Sexually transmitted infections such as herpes, gonorrhea, syphilis and others increase the amount of HIV in semen and vaginal fluid. Other active viral infections (egg influenza, adenoviral infections, coxackie infections) may also have an effect on the increase in viral load. Mutations that lead to drug resistance usually occur in conditions where anti-HIV therapy is received and at the same time, an elevated amount of the virus is present in the blood. Therefore, PCR viral load test should be done regularly every three months during therapy. One of the main goals of anti-HIV therapy, according to majority of guidelines, is to reduce the viral load to an immeasurable amount (below 50 copies / $\mathrm{mL}$ ). A combination of three or more drugs will lead to this desired result in 50-80\% of patients. If such a low viral load is achieved, it will probably prevent the development of resistance, so that combination of drugs can be used for a long period. Based on the CD4 + Tlymphocyte test and the beginning of therapeutic treatment for HIV infection, the level reached is called the starting point and usually takes 3-6 months and sometimes longer to stabilize from the moment of infection. Subsequently, the number of CD4 + cells gradually decreases over the years. On average, CD4 cell count drops by about 50 cells / mm3 each year. The speed of progression is not the same among all the patients, and it can be either faster or slower. In patients who have not been on anti-HIV therapy, CD4 cell count is more important for health orientation than viral load. (33) Onolam is an herbal remedy that contributes to the uplift and stabilization of CIO and HIO. It is very important, for the patient's confidence, willingness and overall well-being to use Onolam herbal remedy in addition to basic conventional therapy. Along with administering the herbal remedy, the patient should always be offered co-operation in the form of friendly conversation, support and trust. (34).

\section{CONCLUSIONS}

The usage of herbal remedy in terms of treating STD is attracting more and more attention nowadays. HIV/AIDS patients often seek for additional herbal therapy support mainly due to unsatisfactory effects, high cost, non-availability, or adverse effects of conventional medicines.

The results of clinical trials of the effects of the herbal preparation "Onolam" along with antiretroviral drugs in patients with HIV / AIDS infection have shown their efficacy in terms of better quality of life due to non-progression of HIV, maintenance of CD4 cell count, stable viral load, and psychological status of the subjects. 
Almost all sexually transmitted diseases can be treated with supportive phytotherapy, besides the primary conventional therapy. In the present era of resistance towards many medications, phytotherapy contributes to the successful management of these infections.

Complementary and alternative medicine (CAM) refers to the use of medical products that are not part of standard medical therapy, but along with conventional medicines used in national health systems, represent significant, additional support not only to patients but also to healthcare systems as a whole, probably because they are based on the results of knowledge and practice from ancient times to the present day.

Currently, the use of CAM in the world is on the rise and it is increasingly becoming an integral part of successful medical therapy, especially in countries where traditional medicine has deep heritage. Phytotherapy or nutritional supplements are mostly used in the various CAM modalities, based on common practices in parts of the world where traditional medicine is long lasting and strong, such as China, Africa and India. Many patients seek for traditional healers before visiting hospitals where they are treated with ART therapy.

\section{REFERENCES}

1. Gerd Gross, Stephen K.,Tyring S. (2011): Sexualytransmited infection and sexually transmited diseases. Haidelberg: Springer Verlange, P20, ISBN 7983642146633.

2. Centers for Disease Control and Prevention (2006): Sexually transmitted diseases, treatment guidelines. MMVR Recom.Rep. 51(RR6): 66-67. PMID 12184549.

3. May MT, Ingle SM(2011):. "Life expectancy of HIV-positive adults: a review". Sexual Health. 8(4): 52633. doi:10.1071/SH11046. PMID 22127039.

4. Bogdanka Andric, Bogdan Pajovic and Milena Djurovic (2019): Urinarytract infections and Sexual transmitted diseases. 3 260, ISBN 978-86-85733-29-1, COBIS.CG-ID 39214096

5. Attia S, Egger M, Müller M, Zwahlen M, Low N (July 2009). "Sexual transmission of HIV according to viral load and antiretroviral therapy: systematic review and meta-analysis". AIDS. 23 (11): 13971404. doi:10.1097/QAD.0b013e32832b7dca. PMID 19381076.

6. Lohse N, Hansen AB, Gerstoft J, Obel N.(2007):Improved survival in HIV-infected persons: consequences and perspectives. J AntimicrobChemother 2007; 60 461-3.| Improved survival in HIV-infected persons: consequences and perspectives.Cross ref $\mid$ GoogleScholarGoogle Scholar |

7. "Retrovirus Definition". AIDSinfo. Archived from the original on December 28, 2019. Retrieved December 28, 2019.

8. Serrano-Villar S, Gutierrez C, Vallejo A, Hernandez-Novoa B, Diaz L, et al. (2013): The CD4/CD8 ratio in HIV infected subjects is independently associated with T-cell activation despite long-term viral suppression. J. Infect 2013; 66:57-66. pmid:23046968. PubMed/NCBI, Google Scholar

9. Guiguet M, Boué F, Cadranel J, et al (2009) ; Clinical Epidemiology Group of the FHDH-ANRS CO4 cohort. Effect of immunodeficiency, HIV viral load, and antiretroviral therapy on the risk of individual malignancies (FHDH-ANRS CO4): A prospective cohort study. Lancet Oncol.;10:1152-1159.

10. Beard J, Feeley F, Rosen S (2009). "Economic and quality of life outcomes of antiretroviral therapy for HIV/AIDS in developing countries: a systematic literature review". AIDS Care.21(11): 134356. doi:10.1080/09540120902889926. PMID 20024710. 
11. Alimonti JB, Ball TB, Fowke KR (2003). "Mechanisms of CD4+ T lymphocyte cell death in human immunodeficiency virus infection and AIDS". The Journal of General Virology. 84 (Pt 7): 1649-61. doi:10.1099/vir.0.19110-0. PMID 12810858.

12. Shelburne $S$ A.,Montes M.,\& Hamill $R$ J. (2006): Immune reconstruction inflammatory syndrome: more answers, more questions. Journal of Antimicrobial Chemotherapy. : 57(2): 167-170, doi:10.1093/jac/dki444 (Pub Med)

13. Deiffenbach C W.,Fauci AC.(2011),: Thirty years of HIV and AIDS: future challenges and opportunities. Annals of Internal Medicine : 154 (11):766-771, doi:10.7326/00003-4819-154-11-201106070-00345 (Pub Med)

14. Serlin M H \& Dieterich D.(2008): Global HIV/AIDS medicine. Elsevier 2008, Capter 23 - gastrointestinal discorders in HIV : pp.251-260 (Google Scholar).

15. Siegfried NL, Uthman OA, Rutherford GW.(2010): Optimal time for initiation of antiretroviral therapy for asymptomatic, HIVinfected, treatment-naive adults. Cochrane Database of Systematic Reviews. 2010;2010(2 (In press)) [PMC free article] [PubMed]

16. Severe P, Pape J, Fitzgerald D, et al. (2009): A randomized clinical trial of early versus standard antiretroviral therapy for HIV-infected patients with a CD4 cell count of 200-350 cells $/ \mathrm{mm}^{3}$ (CIPRATH-001); 49th Interscience Conference on Antimicrobial Agents and Chemotherpy; San Fransisco. 2009.

17. Emery S, Neuhaus JA, Phillips AN, Babiker A, Cohen CJ, Gatell JM, et al. (2008): Major clinical outcomes in antiretroviral therapy (ART)-naive participants and in those not receiving ART at baseline in the SMART study. J Infect Dis. 2008; 197(8):1133-44. [PubMed]

18. Günthard HF, Aberg JA, Eron JJ, et al.(2014): International Antiviral Society-USA Panel. Antiretroviral treatment of adult HIV infection: 2014 recommendations of the International Antiviral Society-USA Panel. JAMA. 2014;312(4):410425. [PubMed] [Google Scholar]

19. Moh R.,Daniel C.,Messou E.,Ouassa T.,Gabilard D.,Anazian A. et al. (2007): Incidence and determinants of mortality and morbidity following early antiretroviral therapy initiation in HIV infected adults in West Africa. AIDS : 21 (18):2483-2491 (Pub Med)

20. Violari A, et al. Early antiretroviral therapy and mortality among HIV-infected infants. New England Journal of Medicine. 2008; 359(21):2233-2244. [PMC free article] [PubMed]

21. Guiguet M, Boué F, Cadranel J, et al (2009); Clinical Epidemiology Group of the FHDH-ANRS CO4 cohort. Effect of immunodeficiency, HIV viral load, and antiretroviral therapy on the risk of individual malignancies (FHDH-ANRS CO4): A prospective cohort study. Lancet Oncol; 10:1152-1159.

22. Shelburne SA.,Montes M.,\& Hamill RJ. (2006): Immune reconstruction inflammatory syndrome: more answers, more questions. Journal of Antimicrobial Chemotherapy. : 57(2): 167-170, doi:10.1093/jac/dki444 (Pub Med)

23. Forgarty A, Rawstorne P, Prestage G, Crawford J, Grierson J, Kippax S (2007): Marijuanaas therapy for people living with HIV/AIDS: social and health aspects. AIDS Care 19 (2): 295-301.

24. Zhang $X(2000)$ Integration of traditional and complimentary medicine into national health care systems. J Manipulative PhysiolTher 23: 139-140.

25. David M (1997) Advising Patients who seek alternative medical therapies. Ann Intern Med 27(1): 61-69.

26. Stephen M, Margaret L, Robert M (2003) Complementary and alternative medical practices: training, experiences, and attitudes of a primary care medical school faculty. J Am Board FamPract 16: 318-326. 
27. J. P. Liu, E. Manheimer, and M. Yang, (2005): "Herbal medicines for treating HIV infection and AIDS," Cochrane Database of Systematic Reviews, no. 3, Article ID CD003937, 2005.View at: Publisher Site | Google Scholar

28. Beard J, Feeley F, Rosen S (2009). "Economic and quality of life outcomes of antiretroviral therapy for HIV/AIDS in developing countries: a systematic literature review". AIDS Care.21(11): 134356. doi:10.1080/09540120902889926. PMID 20024710.

29. Bannerman R (1993) Traditional Medicine and Healthcare. Geneva. WHO.

30. Kisangau D, Lyaruu H, Hosea K, Joseph C (2007) Use of traditional medicines in the management of HIV/AIDS opportunistic infections in Tanzania: a case in the Bukoba rural district. J Ethnobiol Ethnomed 10: 24-27

31. Dhalla S, Chan K J, Montaner J S, Hogg RS (2006) Complementary and alternative medicine use in British Columbia- a survey of HIV positive people on antiretroviral therapy. Compl Therap Clin Pract 12(4): 242-248.

32. R. A. Littlewood and P. A. Vanable, "A global perspective on complementary and alternative medicine use among people living with HIV/AIDS in the era of antiretroviral treatment," Current HIV/AIDS Reports, Vol. 8, No. 4, pp. 257-268, 2011. View at: Publisher Site | Google Scholar

33. Hollenburg D, Zakus D, Cook T, Xu X (2008) Re-positioning the role of traditional, complementary and alternative medicine as essential health knowledge in global health: do they still have a role to play? World Health Population 10 (4): 62-75.

34. RamizaIdrizovic (2020): A book of other people's lives. The book in press, National Library of Montenegro

35. Sharma, Garima. "A Critical Study of the Biology Curriculum at Senior Secondary Stage with Respect to Life Skills Education and the HIV/AIDS Education." IASET: International Journal of Library \& Educational Science (IASET: IJLES) 2.3 (2016):110

36. Mbah, Peter. "Non-governmental organizations and public policy on HIV/AIDS in Nigeria, 1986-2006." International Journal of Humanities and Social Sciences (IJHSS) 3.2 (2014): 33-54.

37. Ghojavand, Ghasem, Belgheis Einali, and Marziye Ghaeliniya. "HIV/AIDS knowledge and attitude of adolescents to prevent AIDS in Isfahan City." International Journal of Environment, Ecology, Family and Urban Studies (IJEEFUS) 3.1 (2013): 6370.

38. Masthanaiah, Tadapatri, and Kadati Ravindra Reddy. "Perceived Sexual Risk Baheviour of HIV/AIDS Among Men Migrant Workers in Mumbai." BEST: International Journal of Humanities, Arts, Medicine and Sciences (BEST: IJHAMS) 2.9 (2014):103-114

39. Andric, Bogdanka, et al. "Co Infectious Participation of Leishmaniasis Parasite In Patients with HIV/AIDS." International Journal of General Medicine and Pharmacy (IJGMP) 8.1 (2019):9-22

40. Afolabi, Adeola Folashade, Adeniyi Olanipekun Fasanu, and Adewale Samson Adeyemi. "Comparison of ELISA and rapid screening tests for the diagnosis of HIV in high risk individuals." International Journal of General Medicine and Pharmacy (IJGMP) 3.2 (2014): 1-8.

41. Adeniji, Adetunji Oladeni, Adewale Samson Adeyemi, and Kola Musliudin Owonikoko. "Pre-Exposure Prophylaxis in SeroDiscordant Male Partners of HIV Positive Women Desirous of Natural Conception." International Journal of General Medicine and Pharmacy (IJGMP) 2.3 (2013):15-22

42. Salilew, Getachew Abiye. "A Mathematical Analysis for Controlling the Spread of HIV/AIDS with Induced Death." TJPRC: International Journal of HIV Medicine \& Research (TJPRC: IJHMR) 1.1 (2016):1-14 

